\title{
Central Signaling Elements of Intercellular Reactive Oxygen/Nitrogen Species-dependent Induction of Apoptosis in Malignant Cells
}

\author{
GEORG BAUER \\ Institute of Virology, Medical Faculty, University Medical Center Freiburg, Freiburg, Germany
}

\begin{abstract}
Intercellular reactive oxygen/reactive nitrogen species-(ROS/RNS)-dependent induction of apoptosis in malignant cells is discussed as a potential control step during oncogenesis. In previous studies, the mechanism of intercellular apoptosis-inducing signaling was mainly established through the use of specific inhibitors and scavengers. Here, a detailed analysis was carried out based on small interfering ribonucleic acid (siRNA)-mediated knockdown of central players of intercellular ROS/RNS signaling and of the mitochondrial and the FAS receptor-dependent pathway of apoptosis. The data show that transforming growth factor $\beta 1$, transforming growth factor $\beta$ receptor, NADPH oxidase-1 (NOX1), NOX1 organizer, and NOXI activator control the $\mathrm{HOCl}$ and the NO/peroxynitrite signaling pathways. Dual oxidase-1 (DUOXI) is specifically involved in $\mathrm{HOCl}$ signaling, and $\mathrm{NO}$ synthase in NO/peroxynitrite signaling. Both pathways utilize intracellular signal transduction through protein kinase $C$ zeta, sphingomyelinase and central elements of the mitochondrial pathway of apoptosis, whereas the FAS receptor and FAS ligand do not seem to play a role.
\end{abstract}

Selective induction of apoptosis in transformed cells is established either through their interaction with neighboring non-transformed cells or through autocrine apoptotic selfdestruction (1-3). Thereby, the $\mathrm{HOCl}(2,5)$ and the nitric oxide/peroxynitrite (NO/PON) signaling pathways $(2,5,6)$ are the dominant intercellular apoptosis-inducing signaling pathways [reviewed in (5)]. Both pathways are driven by

This article is freely accessible online.

Correspondence to: Georg Bauer, Abteilung Virologie, Institut für Medizinische Mikrobiologie und Hygiene, Hermann-Herder Strasse 11, D-79104 Freiburg, Germany. E-mail: georg.bauer@uniklinikfreiburg.de

Key Words: Apoptosis, small interfering RNA, intercellular ROS/RNS signaling, $\mathrm{HOCl}$ signaling, NO/peroxynitrite signaling. superoxide anions which are generated by membraneassociated NADPH oxidase-1 (NOX1) of malignant cells (4, 7 ) and result in the generation of hydroxyl radicals that induce apoptosis through lipid peroxidation in the cell membrane (8). Mechanisms and the multiple modes of interaction of these pathways have been elucidated through inhibitor and reconstitution experiments [reviewed in $(4,5,9)$ ].

Elimination of transformed cells through selective apoptosis induction mediated by intercellular reactive oxygen species (ROS)-dependent signaling has been discussed as a potential natural tumor-preventive mechanism $(4,10,11)$. This concept is in agreement with the pioneering work of Deichman et al., who have shown that tumor progression requires establishment of resistance to $\mathrm{H}_{2} \mathrm{O}_{2}(12,13)$. Resistance is achieved through the expression of membraneassociated catalase $(8,14,15)$. Catalase interferes with the $\mathrm{HOCl}$ signaling pathway through decomposition of $\mathrm{H}_{2} \mathrm{O}_{2}$ and with $\mathrm{NO} / \mathrm{PON}$ signaling through oxidation of $\mathrm{NO}$ and decomposition of PON $(5,8,16,17)$. Recent quantitative characterization of membrane-associated catalase has shown that localization of catalase on the outside of cells is already associated with the transformed state of the cells, however, at a concentration that is not sufficient to prevent intercellular ROS-dependent signaling (15). Catalase seems to be released by tumor cells and is covalently attached to the cells through the action of transglutaminase-2 (15).

In addition to membrane-associated catalase, tumor cells also carry superoxide dismutase (SOD) on their membrane. SOD has a co-modulatory role through preventing superoxide anion-dependent inhibition of catalase $(9,18)$.

The functional complex of membrane-associated NOX1 and protective catalase and SOD represents a regular characteristic of tumor cells and therefore is a focus for the establishment of novel therapeutic approaches (18-20). The complex signaling chemistry of transformed cells, or tumor cells after inhibition of their membrane-associated catalase, has, so far, been mainly elucidated through inhibitor studies and reconstitution experiments. Small interfering ribonucleic acid (siRNA)-based knockdown of defined 
potential candidates of signaling-relevant molecules as an alternative method for the stringent characterization of essential components of the ROS-driven apoptotic pathway has only been used for the dissection of the roles of NOX1 and dual oxidase-1 (DUOX1) (3). Here an endeavor was made to present a comprehensive picture of inter- and intracellular modulators of ROS-driven intercellular apoptosis induction in malignant cells based on siRNAmediated analysis.

\section{Materials and Methods}

Materials. The NOX1 inhibitor 4-(2-aminoethyl)benzenesulfonyl fluoride (AEBSF), the catalase inhibitor 3-aminotriazole (3-AT), arginine, catalase from bovine liver, $\mathrm{NaOCl}$ (for the generation of $\mathrm{HOCl}$ ), the fast decaying $\mathrm{NO}$ donor diethylamine NONOate (DEA NONOate), the broad-spectrum matrix metalloproteinase (MMP) inhibitor (R)-N4-hydroxy-N1-[(S)-2-(1H-indol-3-yl)-1-methylcarbamoyl-ethyl]-2-isobutyl-succinamide (galardin; GM6001), myeloperoxidase (MPO) from human leukocytes, the inhibitor of NO synthase (NOS) $\mathrm{N}$-omega-nitro-L-arginine methylester hydrochloride (LNAME), the $\mathrm{HOCl}$ scavenger taurine, the NO donor sodium nitroprusside (SNP) and superoxide dismutase (SOD) from bovine liver were obtained from Sigma Aldrich (Schnelldorf, Germany).

The PON decomposition catalyst 5-,10-,15-,20-tetrakis(4sulfonatophenyl)porphyrinato iron(III) chloride (FeTPPS) was obtained from Calbiochem/Merck Biosciences GmbH, Schwalbach, Germany.

The catalase mimetic EUK-8 [manganese $N, N$ '-bis(salicylidene) ethylenediamine chloride] was obtained from Cayman chemicals (Ann Arbor, MI, USA) through Merck Biosciences GmbH, Schwalbach/Ts, Germany.

The mechanism-based peroxidase (POD) inhibitor 4-aminobenzoyl hydrazide $(\mathrm{ABH})$ was obtained from Acros Organics, Geel, Belgium.

Transforming growth factor $\beta 1$ (TGF $\beta 1$ ) was purified from human platelets (21) and kept as a stock solution of $1.5 \mu \mathrm{g} / \mathrm{ml}$ in Eagle's minimum essential medium (EMEM) plus 5\% fetal bovine serum (FBS) (Biochrom, Berlin, Germany) at $-20^{\circ} \mathrm{C}$.

Media for cell culture. Cells were either kept in EMEM containing $5 \%$ FBS, or in RPMI-1640 medium containing 10\% FBS, as indicated for the respective cell lines. FBS was heated for 30 minutes at $56^{\circ} \mathrm{C}$ prior to use. Both media were supplemented with penicillin (40 U/ml), streptomycin $(50 \mu \mathrm{g} / \mathrm{ml})$, neomycin $(10 \mu \mathrm{g} / \mathrm{ml})$, moronal $(10 \mathrm{U} / \mathrm{ml})$ and glutamine $(280 \mu \mathrm{g} / \mathrm{ml})$. All supplements were obtained from Biochrom. Cell culture was performed in plastic tissue culture flasks. Cells were passaged once or twice weekly.

Cells. Nontransformed rat fibroblasts $208 \mathrm{~F}$ and their derivative transformed through constitutive expression of $\mathrm{v}$-src (208Fsrc3) were a generous gift from Dr C. Sers and Dr R. Schäfer, Berlin, Germany and were cultured in EMEM with 5\% FBS and supplemented as indicated above.

The gastric carcinoma cell line MKN-45 was purchased from the Deutsche Sammlung für Mikroorganismen und Zellkulturen, Braunschweig, Germany. Cells were grown in suspension, with some cells attaching to the plastic culture dish, in RPMI-1640, with $10 \%$ serum and supplements as described above. Care was taken to avoid cell densities below $300,000 / \mathrm{ml}$ and above $10^{6} / \mathrm{ml}$.
The human neuroblastoma cell line SHEP was obtained from Dr. J. Roessler, Department of Pediatrics and Adolescent Medicine, University Medical Centre Freiburg, Germany and was cultured in EMEM with 5\% FBS and supplemented as indicated above.

Knockdown by treatment with specific siRNAs. All siRNAs were obtained from Qiagen (Hilden, Germany). The siRNAs directed towards human targets are detailed in Table I, including the respective target sequence and the order information. The sequences of custom made siRNAs are presented in Table II.

SiNOX1-a and siNOX1-b are variants of siRNAs directed to human NADPH oxidase-1. When only of variant of siNOX1 was applied, variant siNOX1-a was used and is termed "siNOX1" in the respective figures. SiDUOX1-a and siDUOX1-b are variants of siRNAs directed to human dual oxidase-1. When only one variant of siDUOX-1 was applied, variant siDUOX1-a was used and is termed "siDUOX1" in the respective figures. No sequence information was available for siRNA directed towards epidermal growth factor receptor (siEGFR) (Hs_EGFR_12 validated siRNA). In the experiment described in Figure 1, two custom-made variants of siRNA directed towards murine inducible NO synthase (siiNOSa and siiNOS-b) were used. (siiNOS-a: target sequence: CCC GGA GCC TTT AGA CCT CAA, sense: r(CGG AGC CUU UAG ACC UCA A)dTdT; antisense: r(UUG AGG UCU AAA GGC UCC G)dGdG; siiNOS-b: target sequence:CCG ATT TAG AGT CTT GGT GAA, sense: r(GAU UUA GAG UCU UGG UGA A)dTdT; antisense: r(UUC ACC AAG ACU CUA AAU C)dGdG).

SiRNAs were dissolved in suspension buffer supplied by Qiagen at a concentration of $20 \mu \mathrm{M}$. Suspensions were heated at $90^{\circ} \mathrm{C}$ for 1 minute, followed by incubation at $37^{\circ} \mathrm{C}$ for $60 \mathrm{~min}$. Aliquots were stored at $-20^{\circ} \mathrm{C}$.

Before transfection, $88 \mu \mathrm{l}$ of medium without serum and without antibiotics were mixed with $12 \mu$ l Hyperfect solution (Qiagen) and the required volume of specific siRNA or control siRNA to reach the desired concentration of siRNA during transfection (the standard concentration of siRNA was $24 \mathrm{nM}$ for MKN-45 cells and $10 \mathrm{nM}$ for 208 Fsrc3 cells). The mixture was treated by a vortex mixer for a few seconds and then allowed to sit for $10 \mathrm{~min}$. It was then gently and slowly added to $300,000 \mathrm{MKN}-45$ cells in $1 \mathrm{ml}$ RPMI-1640 medium containing $10 \%$ FBS and antibiotics (12-well plates) or to 200,000 208 Fsrc 3 cells/well in $2.3 \mathrm{ml}$ medium supplemented with 5\% FBS and antibiotics (6-well plates). The cells were incubated at $37^{\circ} \mathrm{C}$ in $5 \% \mathrm{CO}_{2}$ for $24 \mathrm{~h}$. Transfected cells were centrifuged and resuspended in fresh medium at the required density before use.

Determination of the efficiency of siRNA-mediated knockdown. The siRNA transfection system as described above had been optimized to allow a reproducible transfection efficiency of more than $95 \%$ of the cells and to avoid toxic effects (Bauer, unpublished data).

The efficiency of specific knockdown of transforming growth factor $\beta 1$ (TGF $\beta 1)$, its receptor $T G F \beta R$, protein kinase C zeta ( $P K C$ zeta), bcl-2 homologous antagonist/killer $(B A K)$, mitochondriaderived activator of caspases $(D I A B L O)$, epidermal growth factor receptor $(E G F R)$, voltage-dependent anion channel $(V D A C)$, apoptosis protease activating factor $(A P A F)$, caspase-3, caspase-8, caspase- 9 and FASR mRNA had been experimentally determined by the supplier, using real-time quantitative polymerase chain reaction and was found to be more than $90 \%$ for $5 \mathrm{nM}$ siRNA.

The efficiency of knockdown of NOX1, DUOX1 and catalase was based on functional quantitative assays and was more than $90 \%$ (3, 
Table I. Target sequences for siRNAs directed towards human targets.

\begin{tabular}{|c|c|c|c|}
\hline siRNA & Target & Target sequence & Order information \\
\hline siCo & Control (no target) & AAT TCT CCG AAC GTG TCA CGT & Control siRNA \\
\hline siNOX1-a & NADPH oxidase-1 & CCG ACA AAT ACT ACT ACA CAA & Custom made \\
\hline siNOX1-b & NADPH oxidase-1 & CAG GTT TGA GCA GTC ACT TTA & Custom made \\
\hline siNOX3 & NADPH oxidase-3 & CTG GTG AAT AAT AAT TAA CTA & Hs_NOX3_1_HP siRNA \\
\hline siNOX4 & NADPH oxidase-4 & CAA GAT GAC CGT CAC ATT ACA & Hs_NOX4_2_HP siRNA \\
\hline siNOX5 & NADPH oxidase-5 & GAG GAG TGT GAC AAT GAG AAA & Hs_NOX5_2_HP siRNA \\
\hline siNOXO1 & NADPH oxidase organizer-1 & CTG CAG CTG TTG GAA ACC TAT & Hs_NOXO1_2_HP siRNA \\
\hline siNOXA1 & NADPH oxidase activator-1 & CAG GTG GAG CAA GTT GGC AAA & Hs_NOXA1_1_HP siRNA \\
\hline siDUOX1-a & Dual oxidase- 1 & CCA GTC TAA CAC CAC AAC TAA & Custom made \\
\hline siDUOX1-b & Dual oxidase-1 & CCC GGG CAG ATC CGT GTG GTA & Custom made \\
\hline siiNOS2 & Inducible NO synthase-2 & CTG GGC CGT GCA AAC CTT CAA & Custom made \\
\hline $\operatorname{sinNOS}$ & Neuronal NO synthase & CAC AAG TGT GTC GAT CTT AGA & Custom made \\
\hline siTGF $\beta 1$ & Transforming growth factor $\beta 1$ & CAG CAT ATA TAT GTT CTT CAA & Hs_TGFB1_6_HP Validated \\
\hline siTGF $\beta R$ & Transforming growth factor $\beta$ receptor & TCG GTT AAT AAC GAC ATG ATA & Hs_TGFBR2_7_HP Validated \\
\hline siPKCzeta & Protein kinase $\mathrm{C}$ zeta & GAC CAA ATT TAC GCC ATG AAA & Hs_PRKCZ_6_HP Validated \\
\hline siSMase & Acidic sphingomyelinase & TGG AAT TAT TAC CGA ATT GTA & Hs_SMPD1_1_HP siRNA \\
\hline siBAK & BCL2 homologous antagonist/killer & AAG CGA AGT CTT TGC CTT CTC & Hs_BAK1_5_HP Validated \\
\hline siDIABLO & Mitochondria-derived activator of caspases & AAT GCG TTG ATT GAA GCT ATT & Hs_DIABLO_5_HP Validated \\
\hline siVDAC & Voltage-dependent anion channel-2 & AAA ATA CAA GTG GTG TGA GTA & Hs_VDAC2_5_HP Validated \\
\hline siCYTc & Cytochrome c & AGG CAT ATG CCT GAT GAA GTA & Hs_CYCS_6_HP siRNA \\
\hline SiAPAF & Apoptosis protease activating factor & AAG AGC AGC TAT GCT GAT TAA & Hs_APAF1_15_HP Validated \\
\hline siCASP3 & Caspase-3 & CTG AGA TGG GTT TAT GTA TAA & Hs_CASP3_7_HP Validated \\
\hline siCASP8 & Caspase- 8 & AAG AGT CTG TGC CCA AAT CAA & Hs_CASP8_11_HP Validated \\
\hline siCASP9 & Caspase-9 & CAG TGA CAT CTT TGT GTC CTA & Hs_CASP9_7_HP Validated \\
\hline siFASR & FAS receptor & AAG GAG TAC ACA GAC AAA GCC & Hs_FAS_7_HP Validated \\
\hline siFASL & FAS ligand & ATC GGT GAA ACT AAC AGA TAA & Hs_FASLG_1_HP siRNA \\
\hline siMMP2 & Matrix metalloprotease-2 & CAG GCT CTT CTC CTT TCA CAA & Hs_MMP2_5_HP Validated \\
\hline siSODm & Mitochondrial superoxide dismutase & ATC GTT ATG CTG AGT ATG TTA & custom made \\
\hline
\end{tabular}

15). The efficiency of knockdown of iNOS, neuronal NO synthase $(n N O S)$, acidic sphingomyelinase (SMAse), NADPH oxidase organizer-1 (NOXO1), NADPH oxidase activator-1 (NOXAl), cytochrome $\mathrm{c}$ and mitochondrial SOD was proven through complete block of apoptosis after knockdown.

Autocrine ROS/RNS-mediated apoptosis induction. Transformed cells: 208Fsrc3 cells were seeded in 96-well plates at 12,500 cells/well with $100 \mu \mathrm{l}$ medium and $20 \mathrm{ng} / \mathrm{ml}$ TGF $\beta 1$. All assays were performed in duplicate. The assays were cultivated at $37^{\circ} \mathrm{C}, 5 \% \mathrm{CO}_{2}$ for 22 or $42 \mathrm{~h}$ and then the percentage of apoptotic cells was determined. For control, nontransformed $208 \mathrm{~F}$ cells were cultivated under the same conditions.

Tumor cells: When seeded at appropriate density as well as cell number, tumor cells (in the presence of an inhibitor or inactivator of their protective catalase) establish apoptosis-inducing intercellular ROS/RNS signaling. Assays were performed in 96-well plates with $100 \mu \mathrm{l}$ of complete medium per well and contained either 12,500 MKN-45 cells or 10,000 SHEP cells per well. The assays received $0-160 \mathrm{mM}$ of the catalase inhibitor 3-AT for the reactivation of intercellular ROS/RNS signaling. All assays were performed in duplicate. The plates were incubated at $37^{\circ} \mathrm{C}$ in an atmosphere of $5 \% \mathrm{CO}_{2}$. The percentages of apoptotic cells were then determined after 3.5-4 h for MKN-45 cells and 5-6 $\mathrm{h}$ for SHEP cells as described below.
Table II. Sequences of custom-made siRNAs directed towards human targets

\begin{tabular}{|c|c|c|}
\hline siRNA & & Sequence information \\
\hline siNOX1-a & $\begin{array}{l}\text { sense: } \\
\text { antisense: }\end{array}$ & $\begin{array}{l}\text { r(GAC AAA UAC UAC UAC ACA A)dTdT, } \\
\text { r(UUG UGU AGU AGU AUU UGU C)dGdG }\end{array}$ \\
\hline siNOX1-b & $\begin{array}{l}\text { sense: } \\
\text { antisense: }\end{array}$ & $\begin{array}{l}\text { r(GGU UUG AGC AGU CAC UUU A)dTdT, } \\
\text { r(UAA AGU GAC UGC UCA AAC C)dGdG }\end{array}$ \\
\hline siDUOX1-a & $\begin{array}{l}\text { sense: } \\
\text { antisense: }\end{array}$ & $\begin{array}{l}\text { r(AGU CUA ACA CCA CAA CUA A)dTdT } \\
\text { r(UUA GUU GUG GUG UUA GAC U)dGdG }\end{array}$ \\
\hline siDUOX1-b & $\begin{array}{l}\text { sense } \\
\text { antisense: }\end{array}$ & $\begin{array}{l}\mathrm{r}(\mathrm{CGG} \text { GCA GAU CCG UGU GGU A)dTdT, } \\
\mathrm{r}(\mathrm{UAC} \text { CAC ACG GAU CUG CCC G)dGdG }\end{array}$ \\
\hline siiNOS2 & $\begin{array}{l}\text { sense } \\
\text { antisense: }\end{array}$ & $\begin{array}{l}\text { r(GGG CCG UGC AAA CCU UCA A)dTdT } \\
\text { r(UUG AAG GUU UGC ACG GCC C)dAdG }\end{array}$ \\
\hline $\operatorname{sinNOS}$ & $\begin{array}{l}\text { sense: } \\
\text { antisense: }\end{array}$ & $\begin{array}{l}\text { r(CAA GUG UGU CGA UCU UAG A)dTdT; } \\
\text { r(UCU AAG AUC GAC ACA CUU G)dTdG }\end{array}$ \\
\hline siSODm & $\begin{array}{l}\text { sense: } \\
\text { antisense: }\end{array}$ & $\begin{array}{l}\mathrm{r}(\mathrm{CGU} \text { UAU GCU GAG UAU GUU A)dTdT } \\
\text { r(UAA CAU ACU CAG CAU AAC G)dAdT }\end{array}$ \\
\hline
\end{tabular}

Where indicated, inhibitors were added to assays at the following final concentrations: AEBSF: $100 \mu \mathrm{M}$, taurine: $50 \mathrm{mM}$, FeTPPS: $20 \mu \mathrm{M}$, L-NAME: $2.4 \mathrm{mM}$, galardin: $10 \mu \mathrm{M}$. 

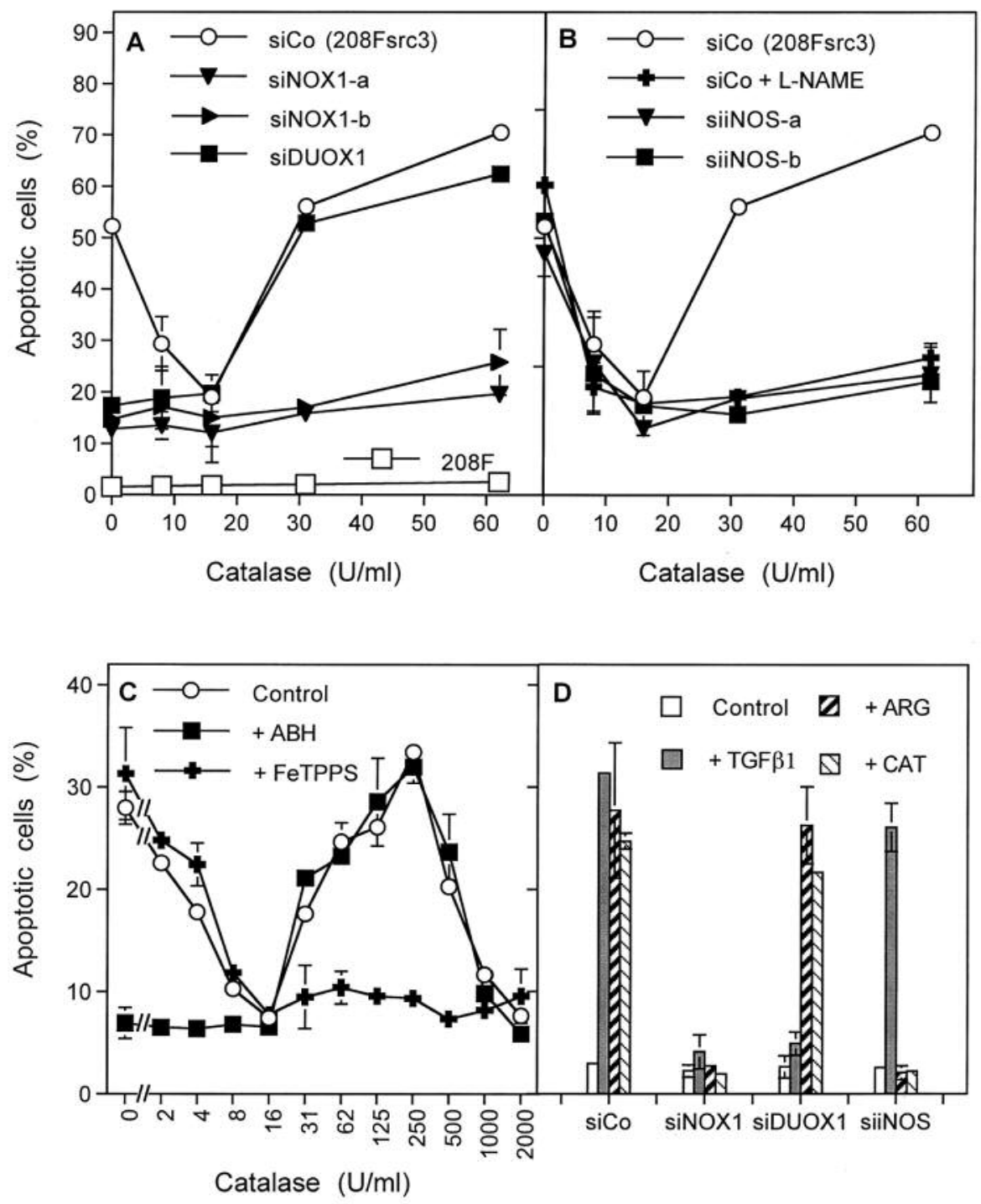

Figure 1. Small interfering ribonucleic acid (siRNA)-based analysis of the molecular players involved in HOCl and nitric oxidelperoxynitrite (NO/PON) signaling in transformed cells. Src oncogene-transformed $208 F s r c 3$ cells show autocrine apoptosis induction in contrast to their nontransformed parental cells 208F. Exogenous catalase leads to a biphasic curve of apoptosis induction. SiRNA-based knockdown of NADPH oxidase1 (NOX1) by two variants of siRNA directed towards NOX1 (siNOX1-a, siNOX1-b) abrogates apoptosis at all concentrations of catalase (A), whereas siRNA directed towards dual oxidase-1 (siDUOX1) and two variants of siRNA directed NO synthase (siiNOS-a, siiNOS-b) as well as an inhibitor of NOS [N-omega-nitro-L-arginine methylester hydrochloride (L-NAME)] act at different concentration ranges of catalase (B). This shows that $\mathrm{HOCl}$ signaling is inhibited by catalase, followed by resumption of NO/PON signaling. C: Apoptosis induction in $208 \mathrm{Fsrc} 3$ cells in the presence of a wide concentration range of catalase shows HOCl signaling [inhibited by the peroxidase inhibitor 4-aminobenzyoyl hydrazide (ABH)], followed by an optimum curve of NO/PON signaling inhibited by 5-,10-,15-,20-tetrakis(4-sulfonatophenyl)porphyrinato iron(III) chloride (FeTPPS). D: $208 F$ src 3 cells in the absence of exogenous transforming growth factor $\beta 1$ (TGF $\beta 1$ ) (control) did not show apoptosis induction, whereas exogenous TGF $\beta 1(20 \mathrm{ng} / \mathrm{ml})$ caused activation of $\mathrm{HOCl}$ signaling, while addition of arginine $(0.75 \mathrm{mM})$ or catalase (100 U/ml) caused selective activation of NO/PON signaling, as seen from the differential effect of knockdown of DUOX or iNOS.

Apoptosis induction by exogenous $\mathrm{HOCl}$. A total of $10,000 \mathrm{MKN}$ 45 cells (pretreated with siRNAs for $24 \mathrm{~h}$ ) in $100 \mu$ complete medium in 96-well plates received $80 \mu \mathrm{M} \mathrm{HOCl}$. Assays were performed in duplicate. The percentages of apoptotic cells were determined 1 hour after the addition of $\mathrm{HOCl}$.
Apoptosis induction by addition of the NO donor DEA NONOate. A total of $10,000 \mathrm{MKN}-45$ cells (pretreated with siRNAs for 24 hour) in $100 \mu \mathrm{l}$ complete medium in 96-well plates received 10 $\mathrm{mM}$ 3-AT and $0.5 \mathrm{mM}$ DEA NONOate. Assays were performed in duplicate. The percentages of apoptotic cells were determined 1 
hour after addition of the NO donor. Apoptosis induction mediated by DEA NONOate is caused by PON that is formed through the interaction of $\mathrm{NO}$ derived from the $\mathrm{NO}$ donor and NOX1-derived superoxide anions, and requires inhibition of membrane-associated catalase by 3 -AT (6).

Determination of the percentage of apoptotic cells. The percentage of apoptotic cells was determined by inverted phase-contrast microscopy based on the classical criteria for apoptosis, i.e. nuclear condensation or fragmentation and membrane blebbing (22-25). At least $2 \times 200$ cells were scored for each point of measurement in duplicate assays.

Determination of superoxide anion production. A total of 12,500 MKN-45 cells (pretreated for $24 \mathrm{~h}$ with siRNAs) were cultivated in $100 \mu \mathrm{l}$ of complete medium in 96-well tissue culture clusters in duplicate assays. SOD ( $\mathrm{Cu} / \mathrm{Zn}$ SOD from bovine liver) was added at 0-7 $\mathrm{U} / \mathrm{ml}$ in twofold dilution steps. Apoptosis was induced through addition of $120 \mu \mathrm{M}$ EUK-8, which establishes HOCl-dependent apoptosis induction (8). After $4 \mathrm{~h}$ of incubation at $37^{\circ} \mathrm{C}$ in $5 \% \mathrm{CO}_{2}$, the percentage of apoptotic cells was determined by inverted phasecontrast microscopy as described above. This specific feature of the action of $\mathrm{Cu} / \mathrm{Zn}-\mathrm{SOD}$ with its characteristic curve facilitates the relative quantification of the extracellular superoxide anion concentration $(26,27)$, as there is a linear relationship between superoxide anion concentration and SOD required for optimal inhibition. As SOD does not penetrate the cells, only extracellular superoxide anions are determined.

Determination of peroxidase release. The assay follows the principles that were recently described $(26,28)$. MKN-45 cells, pretreated with siRNAs for 24 hours were washed and cultivated at a density of 300,000 cells $/ \mathrm{ml}$ for an additional $24 \mathrm{~h}$. The assays also contained $20 \mathrm{ng} / \mathrm{ml} \mathrm{TGF} \beta 1$ or $10 \mu \mathrm{M}$ galardin. At the end of the incubation, cells were centrifuged and the supernatants were analyzed for peroxidase. The determination of peroxidase was based on destruction of $\mathrm{HOCl}$ generated by EUK-8 by natural peroxidase (8). A total of $10,000208 \mathrm{Fsrc} 3$ cells/per $100 \mu \mathrm{l}$ medium in the presence of $20 \mathrm{ng} / \mathrm{ml}$ TGF $\beta$ and $75 \mu \mathrm{M}$ EUK- 8 were cultivated in the presence of increasing addition of supernatants to be tested. Apoptosis induction was determined after $4 \mathrm{~h}$. The resultant competition curves were compared to competition by MPO as reference. In order to ensure that peroxidase activity was measured in this competition test, some assays were cultivated in the presence of the peroxidase inhibitor $\mathrm{ABH}$. Abrogation of the competition reaction by $\mathrm{ABH}$ ensures that indeed peroxidase had cause the competition measured.

Statistical analysis. Assays were performed in duplicate, unless otherwise stated. The empirical standard deviation was calculated and is shown in the figures. Absence of standard deviation bars for certain points indicates that the standard deviation was too small to be reported by the graphic program. Empirical standard deviations were calculated merely to determine how close the results were obtained in parallel assays within the same experiment and not with the intention of statistical analysis of variance. The Yates continuity corrected chi-square test was used for the statistical determination of significances.

For clarity, some figures use a logarithmic scale annotated with the actual concentration applied.

\section{Results}

Central elements for extracellular signaling mechanisms in transformed cells. In the presence of TGF $\beta 1$, src oncogenetransformed rat fibroblasts 208Fsrc3 (transfected with control siRNA) showed autocrine apoptosis induction $(p<0.001)$, whereas their nontransformed parental cells did not (Figure $1 \mathrm{~A}$ and $\mathrm{B})$. Addition of gradually increasing concentrations of catalase up to $20 \mathrm{U} / \mathrm{ml}$ caused inhibition of apoptosis $(p<0.001)$. At concentrations of more than $20 \mathrm{U} / \mathrm{ml}$ catalase, apoptosis induction resumed $(p<0.001)$. Knockdown of NOXI by two siRNA variants directed towards NOX1 caused complete inhibition of apoptosis at all concentrations of catalase $(p<0.001)$. At concentrations of less than $20 \mathrm{U} / \mathrm{ml}$, catalase knockdown of DUOX caused complete inhibition of apoptosis $(p<0.001)$, whereas knockdown of iNOS by two variants of siiNOS or inhibition of NOS by L-NAME had no inhibitory effect. At concentrations of catalase higher than 20 $\mathrm{U} / \mathrm{ml}$, apoptosis induction was completely inhibited by knockdown or inhibition of $\operatorname{NOS}(p<0.001)$, whereas knockdown of DUOX had no effect.

In a control experiment, addition of catalase at a wider concentration range (Figure 1C) confirmed the initial inhibition of apoptosis induction by catalase $(p<0.001)$, followed by resumption of apoptosis induction up to an optimum at $250 \mathrm{U} / \mathrm{ml}$ catalase $(p<0.001)$. Higher concentrations of catalase then caused inhibition of apoptosis $(p<0.001)$.

Apoptosis induction in 208Fsrc3 cells in the presence of TGF $\beta 1$ was confirmed to depend on NOX1 $(p<0.001)$ and DUOX1 $(p<0.001)$ and to be independent of iNOS (Figure 1D), whereas apoptosis induction in the presence of $100 \mathrm{U} / \mathrm{ml}$ catalase was independent of DUOX1, but dependent on NOX1 $(p<0.001)$ and iNOS $(p<0.001)$. The addition of the NOS substrate arginine had the same effect as the presence of catalase.

Central elements for extracellular signaling mechanisms in tumor cells. In order to study the signaling chemistry of reactivated intercellular ROS/RNS signaling after inhibition of catalase of tumor cells, human MKN-45 gastric carcinoma cells were transfected with irrelevant control siRNA (siCo) or with siRNAs directed towards NOX1, DUOX1 and iNOS. One day after transfection, siCo-transfected cells were treated with increasing concentrations of the catalase inhibitor 3-AT, in the absence of inhibitors or in the presence of the $\mathrm{HOCl}$ scavenger taurine, the PON decomposition catalyst FeTPPS or the NOX1 inhibitor AEBSF (Figure 2A). In parallel, apoptosis induction by increasing concentrations of 3-AT in siCo-transfected MKN-45 cells was compared to that in siDUOX1-, siiNOS- and siNOX1-transfected cells (Figure 2B). SiCo-transfected cells showed an optimum curve for apoptosis induction by 3 -AT $(p<0.001)$. At all concentrations of 3-AT, apoptosis induction was inhibited by 


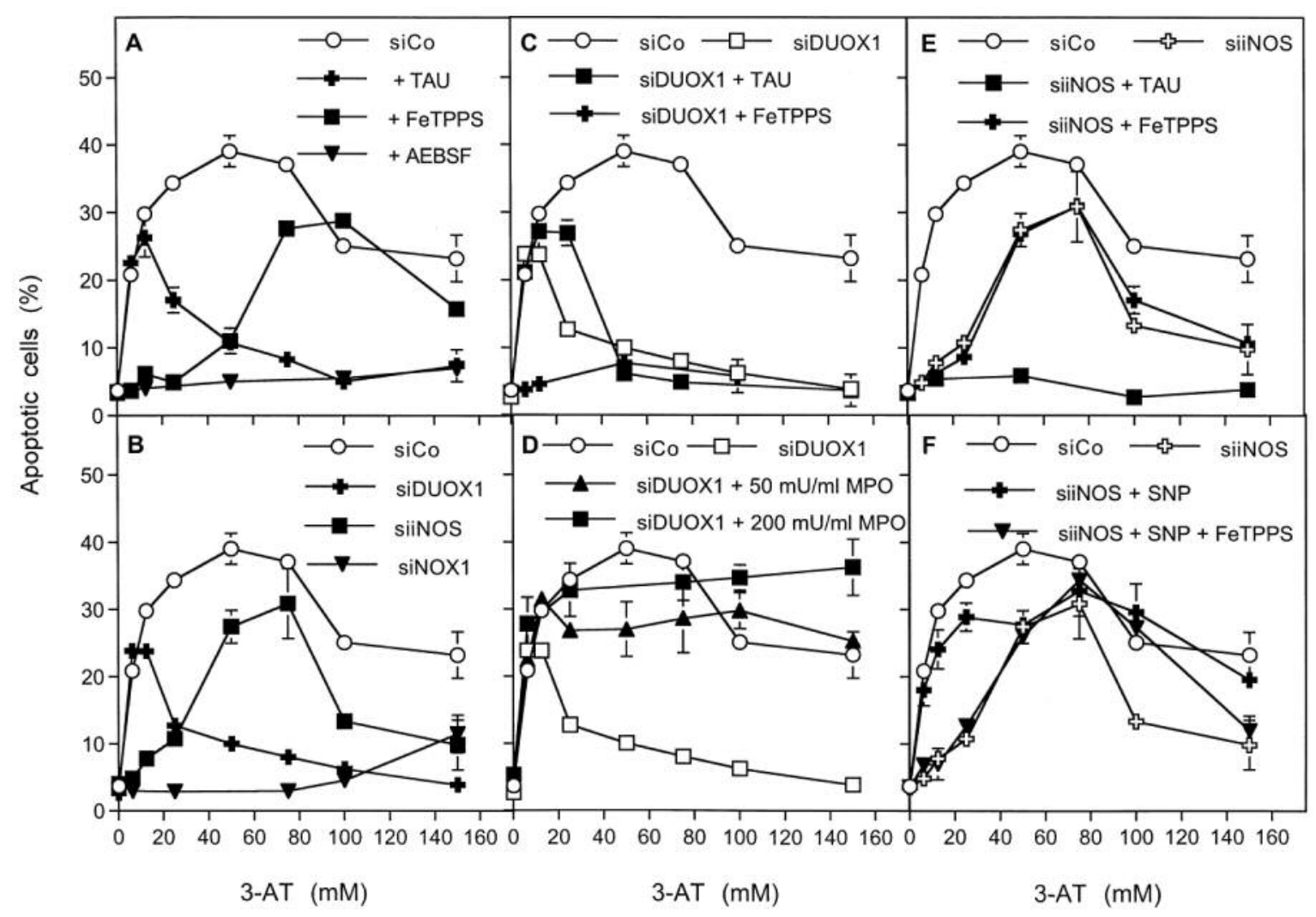

Figure 2. Small interfering ribonucleic acid (siRNA)-based analysis of reactive oxygen species/reactive nitrogen species (ROS/RNS) signaling in tumor cells after gradual inhibition of catalase by 3-aminotriazole (3-AT). A: The HOCl scavenger taurine (TAU) and the peroxynitrite decomposition catalyst 5-,10-,15-,20-tetrakis(4-sulfonatophenyl)porphyrinato iron(III) chloride (FeTPPS) allow dissection of autocrine apoptosis induction in $M K N-45$ gastric carcinoma cells in the presence of increasing concentrations of the catalase inhibitor 3-AT into NO/PON and HOCl signaling, whereas the NOX1-inhibitory effect of 4-(2-aminoethyl)benzenesulfonyl fluoride (AEBSF) indicates that both processes are dependent on superoxide anions. B-F. siRNA based knockdown of dual oxidase 1 (siDUOX1), inducible NO synthase (siiNOS) and NADPH oxidase-1 (siNOX1) allow their roles in both pathways to be defined. This is counter-controlled by the additional presence of taurine, FeTPPS and by supplementation with myeloperoxidase $(M P O)$ or the NO donor sodium nitroprusside (SNP) at $15 \mu \mathrm{M}$.

AEBSF $(p<0.001)$, whereas inhibition by FeTPPS was restricted to the lower concentrations of 3-AT $(p<0.001)$ and inhibition by taurine to the higher concentrations of 3-AT $(p<0.001)$. Knockdown of NOXI caused nearly complete inhibition of apoptosis induction at all concentrations of 3-AT $(p<0.001)$ (Figure 2B). siRNA directed towards $i N O S$ caused inhibition of apoptosis induced by low concentrations of 3-AT $(p<0.001)$, in analogy to the PON decomposition catalyst FeTPPS, whereas siRNA towards DUOXI caused a complete inhibition of apoptosis at high concentrations of 3 -AT $(p<0.001)$ and thus paralleled the inhibition pattern of the $\mathrm{HOCl}$ scavenger taurine.

3-AT-mediated apoptosis induction in siDUOX1transfected cells was completely inhibited by FeTPPS $(p<0.001)$, but was not affected by taurine (Figure 2C), indicating that siDUOX1 abrogated $\mathrm{HOCl}$ signaling but did not interfere with NO/PON signaling. Addition of MPO to
siDUOX1-treated cells abrogated the inhibitory effect of siDUOX $(p<0.001)$ (Figure 2D). A complementary result was seen for siiNOS-transfected cells, as i) their residual apoptosis induction was inhibited by taurine $(p<0.001)$; ii) residual apoptosis induction was not affected by FeTPPS, iii) the NO donor SNP abrogated the inhibitory effect of siiNOS $(p<0.001)$, and iv) the abrogating effect of SNP was inhibited by FeTPPS $(p<0.001)$ (Figure $2 \mathrm{E}$ and F).

3-AT-mediated apoptosis induction in MKN-45 cells was completely inhibited through pretreatment with siRNA directed towards TGF $\beta 1 \quad(p<0.001)$, TGF $\beta R \quad(p<0.001)$, PKC zeta $(p<0.001)$ and sphingomyelinase (SMAse) $(p<0.001)$, whereas treatment with siRNA directed towards the EGF receptor only showed a modulatory effect on apoptosis induction (Figure 3AC). The effect of treatment with siTGF $\beta 1$, but not that with siTGF $\beta R$ was completely abrogated through addition of exogenous TGF $\beta 1(p<0.001)$ (Figure 3A and B). 


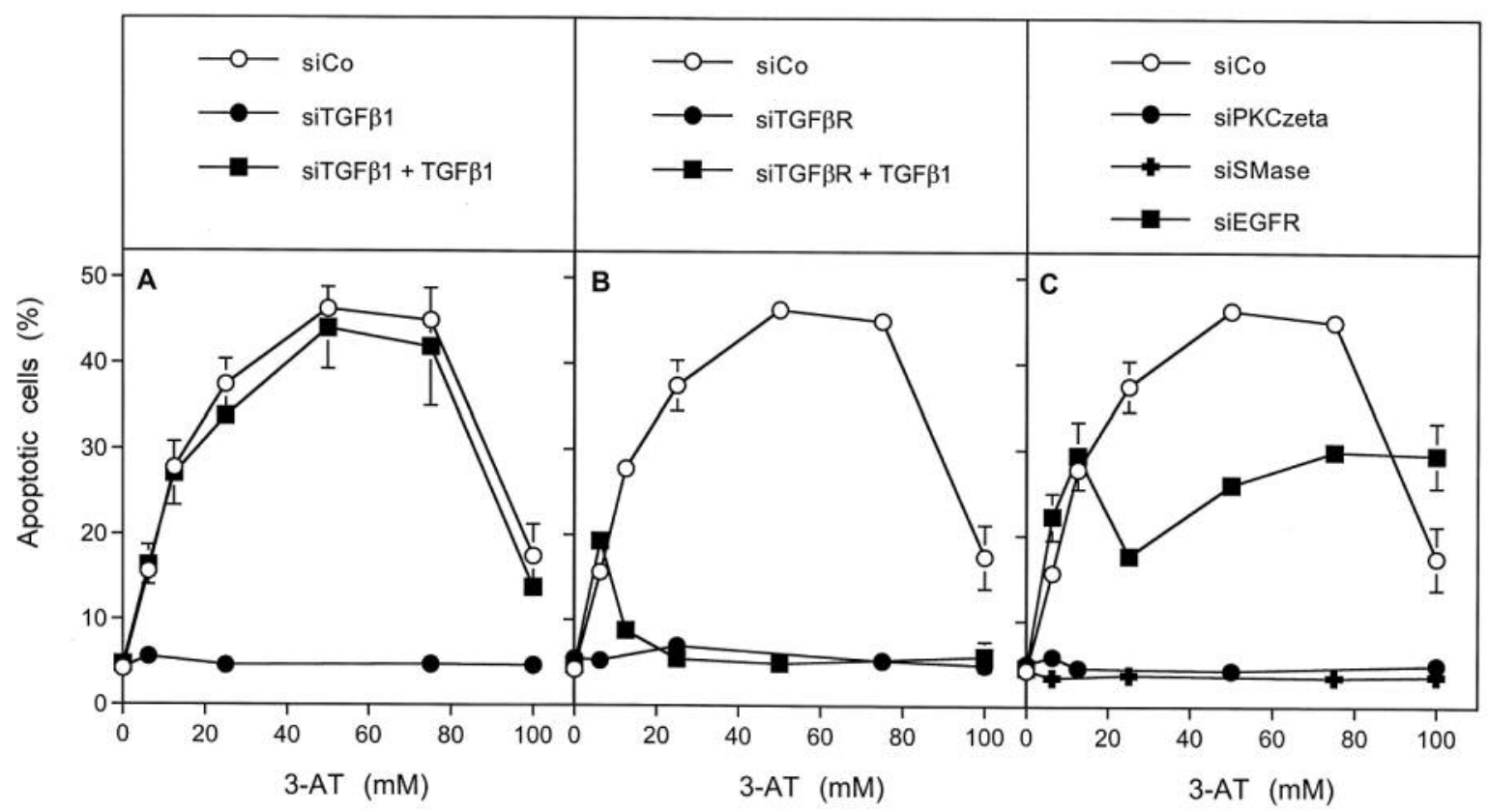

Figure 3. Modulators of autocrine apoptosis induction in MKN-45 tumor cells. Compared to cells transfected with control small interfering ribonucleic acid (siRNA) (siCo), transfection with siRNA directed towards transforming growth factor beta-1 (siTGF 1 1) (A), TGF $\beta$ receptor $($ siTGFRR) (B), protein kinase $C$ zeta (siPKCzeta) or acidic sphingomyelinase (siSMASE) (C) completely prevented apoptosis induction, whereas knockdown of the epidermal growth factor receptor (siEGFR) only caused a slight decrease in apoptosis (C). The effect of knockdown of TGF $\beta 1$ was completely abrogated through supplementation with exogenous TGF $\beta 1$, whereas supplementation with TGF $\beta 1$ had no effect on cells with knockdown of the TGFßR.

Quantitative and functional aspects of NOX1-dependent superoxide anion generation. A recently described functional assay allowed quantification of the relative concentration of extracellular superoxide anions (27). It is based on the bellshaped inhibition curve of superoxide anion-dependent signaling by $\mathrm{Cu} / \mathrm{Zn}$ SOD. Figure $4 \mathrm{~A}$ exemplarily demonstrates the application of this assay and shows that exogenous TGF $\beta 1$ enhanced superoxide anion production about fourfold $(p<0.001)$, whereas siRNA-mediated knockdown of either NOX1 or TGF $\beta 1$ caused a strong reduction in superoxide anion production $(p<0.001)$.

Based on siRNA-mediated analysis and application of this assay system, it was shown that siRNA-mediated knockdown of $T G F \beta R$ had a similar strong inhibitory effect on extracellular superoxide anion production $(p<0.001)$ as knockdown of NOX1 or TGF $\beta 1$, whereas knockdown of DUOX1 had no inhibitory effect (Figure 4B). Supplementation with exogenous TGF $\beta 1$ abrogated the inhibitory effect of siTGF $\beta 1(p<0.001)$, but not that of siTGF $\beta$ R. The inhibition of extracellular superoxide anion generation through treatment with siNOX1 was dependent on the concentration of the siRNA and was paralleled by an inhibition of autocrine apoptosis induction (data not shown), demonstrating the functional relevance of NOX1-dependent superoxide anion generation as well as the potential to modulate the strength of a specific signaling effect through siRNA-based methodology. Quantitative and functional aspects of DUOX1-dependent peroxidase release. A recently described functional assay for the quantiation of peroxidase (28) is characterized by the concentration-dependent inhibition of EUK-8-mediated apoptosis induction $(p<0.001)$, as demonstrated for the reference enzyme MPO in Figure 5A. Inhibition by MPO was abrogated in the presence of the peroxidase inhibitor $\mathrm{ABH}$ $(p<0.001)$, confirming that the enzymatic activity of the peroxidase was responsible for the observed effect. The application of this assay system in combination with specific siRNA-treatment showed that transfection with two different siRNAs directed towards DUOX1 prevented the TGF $\beta 1$ triggered release of peroxidase into the supernatant $(p<0.001)$, whereas control siRNA and siRNA directed towards NOX1 had no inhibitory effect (Figure 5B and C). Addition of the MMP inhibitor galardin to cells treated with siCo prevented the release of peroxidase $(p<0.001)$ and thus pointed to the role of MMP in this system. Treatment with siTGF $\beta$ R caused complete $(p<0.001)$ and siPKC zeta a substantial inhibition $(p<0.001)$ of peroxidase release (Figure 5C).

The role of NOS isoforms for intercellular apoptosis signaling. Whereas knockdown of iNOS was shown to prevent $\mathrm{NO} / \mathrm{PON}$-mediated signaling effects in gastric 
carcinoma cells (Figure 2) and in other cell systems of epithelial or fibroblast lineage (Bauer, unpublished results), apoptosis induction in 3-AT-treated SHEP neuroblastoma cells was not inhibited by siiNOS, but inhibition required siRNA directed towards nNOS $(p<0.001)$ (Figure 6). In line with previous findings that these cells only establish $\mathrm{NO} / \mathrm{PON}$ signaling without contribution of the $\mathrm{HOCl}$ pathway (8), siNOX1 caused an inhibitory effect $(p<0.001)$, but siDUOX1 did not (Figure 6).

The interplay between extracellular and intracellular signaling effects. As reactivation of intercellular ROS/RNSmediated apoptosis signaling in MKN-45 gastric carcinoma cells through inhibition of protective catalase has been shown to be dependent on NO/PON signaling at low concentrations of the catalase inhibitor (such as $6 \mathrm{mM} 3-\mathrm{AT}$ ) and dominating $\mathrm{HOCl}$ signaling at higher concentrations of the inhibitor (such as $75 \mathrm{mM} 3-\mathrm{AT}$ ), whereas no apoptosis induction occurred in the absence of inhibitor (8), siRNAbased analysis should allow for elucidation of the distinctive as well as the common biochemical features of the two signaling pathways (Figure 7). Whereas knockdown of DUOX1 seemed to play no role in NO/PON signaling at 6 mM 3-AT (Figure 7B), its knockdown completely inhibited $\mathrm{HOCl}$ signaling at $75 \mathrm{mM} 3$-AT $(p<0.001)$ (Figure $7 \mathrm{C})$. In contrast, knockdown of iNOS strongly interfered with NO/PON signaling $(p<0.001)$ (Figure 7B), but only had a minor effect on $\mathrm{HOCl}-d e p e n d e n t$ apoptosis induction in the presence of $75 \mathrm{mM}$ 3-AT (Figure 7C). All other components of both signaling pathways and their intracellular effects seemed to be identical, as both pathways required active NOX1, TGF $\beta 1$, TGF $\beta R$, functional PKC zeta and SMAse $(p<0.001)$. Both pathways seemed to depend on functional VDAC, BAK, DIABLO, mitochondrial SOD, and caspase-9 $(p<0.001)$. Both pathways seemed to be independent of the activity of the FAS receptor and caspase- 8 , but required the activity of caspase-9 and caspase- $3(p<0.001)$.

The data established by siRNA-based analysis, as shown in Figure 7, comprise the molecular players that establish intercellular ROS signaling and those that contribute to the intracellular execution of apoptosis induction. In order to selectively focus on the players involved in intracellular apoptosis signaling after application of $\mathrm{HOCl}$ or $\mathrm{NO}, \mathrm{MKN}-$ 45 cells transfected with control siRNA or siRNA directed towards molecular players of interest were either confronted with exogenous $\mathrm{HOCl}$ or the NO donor DEA NONOate, and their apoptotic response was measured. As determined before, the apoptotic response of the tumor cells to $\mathrm{HOCl}$ did not require parallel inhibition of catalase, whereas NOmediated, PON-dependent apoptosis induction did. siRNAbased analysis of apoptosis induction in tumor cells through addition of exogenous $\mathrm{NO}$ or $\mathrm{HOCl}$ showed identical patterns for both pathways (Figures 8 and 9): Both pathways
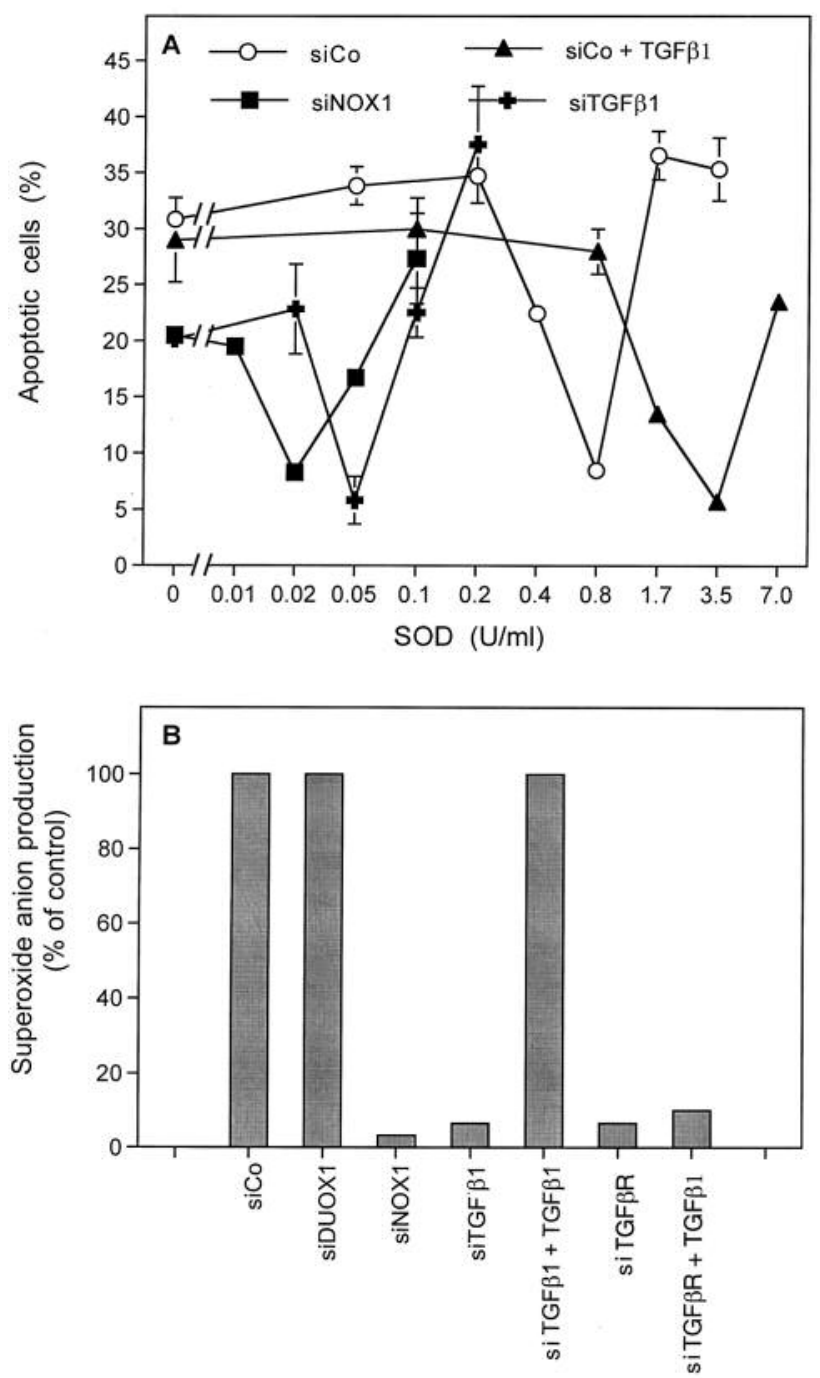

Figure 4. Quantitation of extracellular superoxide anions generated by NADPH oxidase 1 (NOX1). A: An example of quantification of extracellular superoxide anions, based on SOD-mediated inhibition of apoptosis induction (27). Exogenous transforming growth factor beta1 (TGF $\beta 1$ ) increases superoxide anion production (resulting in a rightward shift of the inhibiton curve), whereas siRNA-based knockdown of NADPH oxidase 1 (NOX1) or of TGF $\beta 1$ causes a decrease in superoxide anion production (resulting in a leftward shift of the inhibition curve). B: Quantification of extracellular superoxide anion production by MKN-45 cells transfected with control siRNA (siCo, representing 100\% superoxide anion production) compared to cells with knockdown of dual oxidase-1 (siDUOX1), NOX1, TGFß1 and its receptor (TGF $\beta R$ ), in the absence or presence of exogenous TGF $\beta 1$.

were driven by NOX1, as seen by the effect of knockdown of NOX1, NOXO1 and NOXA1 $(p<0.001)$, whereas knockdown of NOX3, NOX4 and NOX5 had no effect. Importantly, the inhibitory effect of knockdown of NOX1 and its regulators NOXO1 and NOXA1 confirmed that PON 

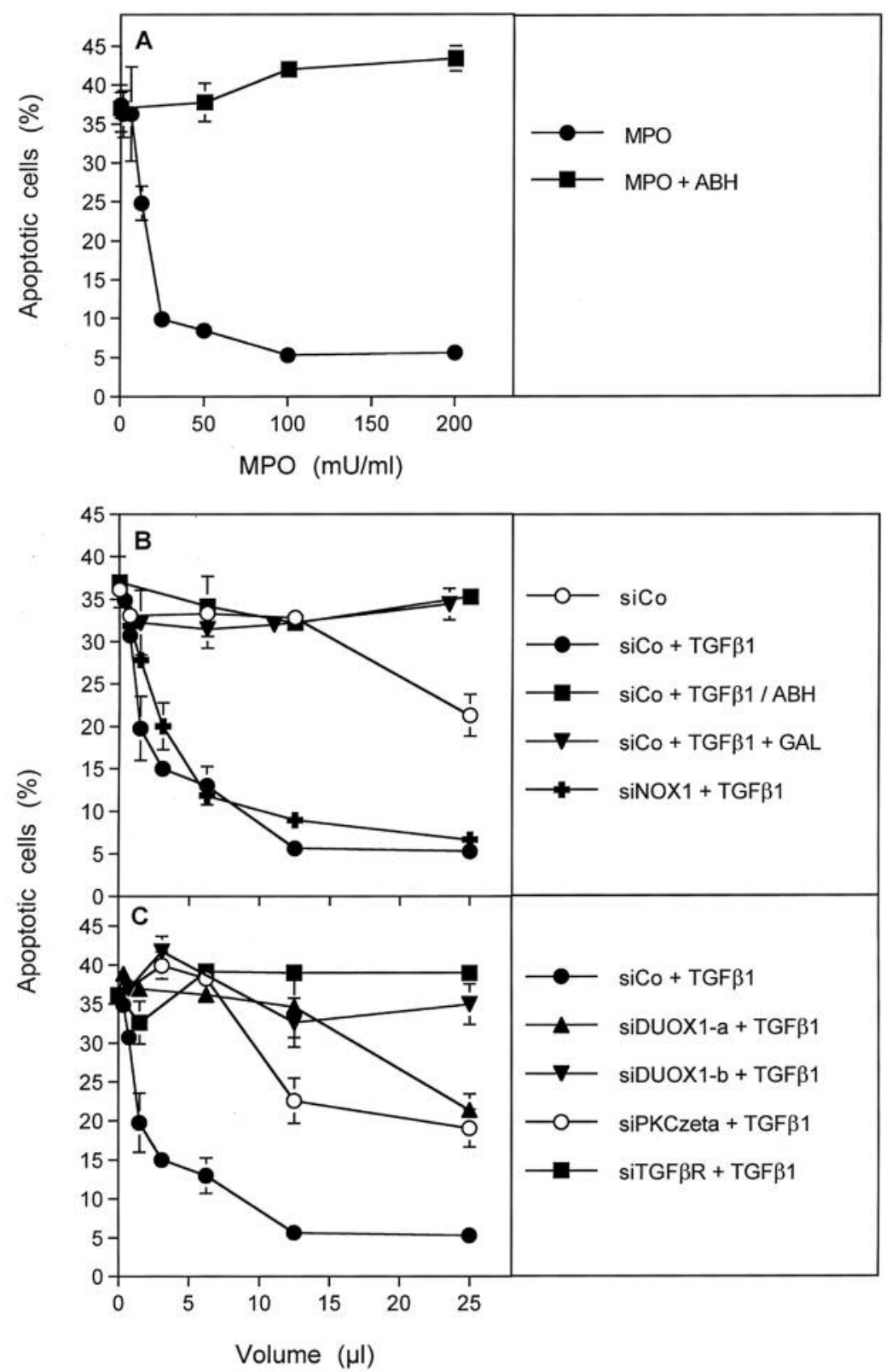

Figure 5. Quantification of peroxidase release. The assay is based on competition of peroxidase in the test sample with the peroxidase activity of EUK-8, which results in a decrease in EUK-8-mediated apoptosis induction (28). A: Reference competition curve for the quantification of myeloperoxidase (MPO) in the competition assay was applied. Competition by MPO was abrogated by the peroxidase inhibitor 4-aminobenzoyl hydrazide $(A B H)$. B: Release of competing peroxidase from MKN-45 cells transfected with control siRNA (siCo) required the action of transforming growth factor beta-1 (TGF $\beta 1)$ and was prevented by the matrix metalloprotease inhibitor galardin (GAL). Inhibition of competition by ABH indicates that the competing activity is based on peroxidase activity. Knockdown of NADPH oxidase-1 (NOX1) did not influence the release of peroxidase. $C$ : Knockdown of dual oxidase-1 (DUOX1) by two variants of siDUOX1, of the TGF $\beta$ receptor (TGF $\beta R$ ) and of protein kinase C zeta (PKC zeta) inhibited the release of peroxidase.

formation through the interaction between NO generated by DEA NONOate and NOX1-derived superoxide anions was essential for apoptosis induction. The dependence of HOClmediated apoptosis induction on NOX1 $(p<0.001)$ and its modulators confirmed that $\mathrm{HOCl} /$ superoxide anion interaction, leading to the generation of hydroxyl radicals is essential for $\mathrm{HOCl}-m e d i a t e d$ apoptosis induction. The role of TGF $\beta 1$, TGF $\beta$ R and PKCzeta for both pathways was also confirmed $(p<0.001)$. Likewise, confirmation of function for SMase and components of the mitochondrial pathway of 
apoptosis (BAK, DIABLO, VDAC, cytochrome c, APAF1, caspase-9) were achieved $(p<0.001)$. As knockdown of the FASR and caspase- 8 had no inhibitory effect on apoptosis induction, the death receptor-mediated FAS pathway does not seem to be required for apoptosis induction by both pathways, whereas caspase- 3 seems to act as final caspase $(p<0.001)$. Knockdown of $M M P 2$ caused inhibition of NO/PON $(p<0.001)$ and of $\mathrm{HOCl}$ signaling $(p<0.001)$, mediated through a peroxidase reaction, as seen through the counter effect of the mechanism based peroxidase inhibitor $\mathrm{ABH}(p<0.001)$.

\section{Discussion}

These data confirm that oncogene-transformed cells that are cultivated at sufficient cell density and cell number show autocrine apoptosis induction, whereas their non-transformed parental cells do not. As transformed cells, in contrast to their nontransformed parental cells, are known to express NOX1 (4, $7,29)$, and as knockdown of NOXl prevented apoptosis induction, this difference can be attributed to the selective expression of NOX1 by transformed cells. Autocrine apoptosis induction by transformed cells is enhanced by the addition of exogenous TGF $\beta 1$. Without addition of TGF $\beta 1$, the kinetics is delayed (9). This finding is explained by the stimulatory role of TGF $\beta 1$ on NOX1 activity (27) and on peroxidase release (28). As apoptosis induction in transformed cells was abrogated through siRNA-based knockdown of NOXI and DUOXI, whereas knockdown of $i N O S$ had no inhibitory effect, it seemed to be exclusively due to $\mathrm{HOCl}$ signaling. This is in line with a previous report (3). As gradual addition of exogenous soluble catalase initially inhibited $\mathrm{HOCl}$ signaling and then allowed for resumption of apoptosis induction that was specifically inhibited by knockdown of iNOS and NOXI (indicative of the NO/PON pathway), it becomes overt that $\mathrm{H}_{2} \mathrm{O}_{2}$ not only fosters $\mathrm{HOCl}$ signaling, but also interferes with $\mathrm{NO} / \mathrm{PON}$ signaling. This counterbalance is further substantiated through the effect of the NOS substrate arginine, which leads to NO/PON signaling and inhibition of DUOX-dependent $\mathrm{HOCl}$ signaling and thus causes an result analogous to that of exogenous catalase, although through a different mechanism. Whereas catalase removes $\mathrm{H}_{2} \mathrm{O}_{2}$ that competes with $\mathrm{NO}$, increased arginase concentration fosters $\mathrm{NO}$ synthesis and in this way competes with $\mathrm{H}_{2} \mathrm{O}_{2}$. Competition between $\mathrm{NO}$ and $\mathrm{H}_{2} \mathrm{O}_{2}$ was recently shown (8) and the complex underlying mechanisms have been discussed (5). Very high concentrations of soluble catalase finally inhibited NO/PON signaling. The high concentration of soluble catalase was required to mimic the inhibitory effect of high local catalase concentration on the surface of tumor cells on NO/PON signaling. This high local concentration is required for kinetic reasons, as catalase has to compete with the generation of PON/peroxynitrous acid in close vicinity to the membrane (8).

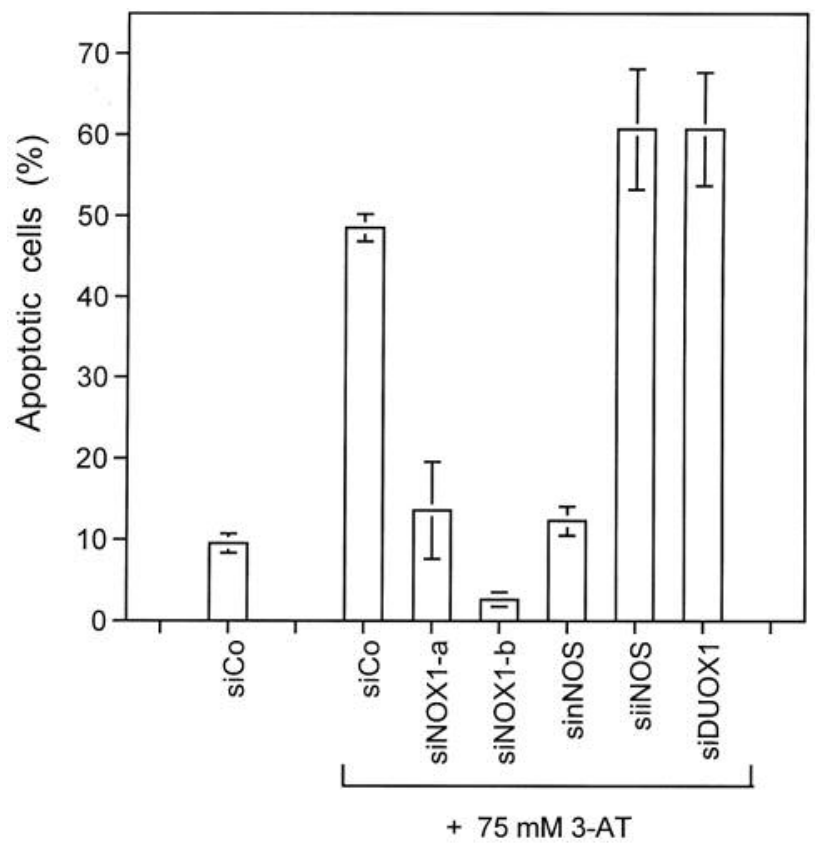

Figure 6. Autocrine apoptosis induction in neuroblastoma cells depends on neuronal NO synthase ( $N N O S$ ) and not on inducible NO synthase (iNOS). Apoptosis induction in SHEP cells transfected with control small interfering ribonucleic acid (siRNA) (siCo) was shown to depend on catalase inhibition by 3-aminotriazole (3-AT) and was prevented by knockdown of NADPH oxidase-1 (NOX1) (by two variants of siNOX1) and knockdown of neuronal NO synthase (nNOS), but not by knockdown of inducible NO synthase (iNOS) or dual oxidase-1 (DUOX1).

When the protective catalase of tumor cells is inhibited and apoptosis induction is reactivated, the same essential players as seen before for ROS/RNS signaling of transformed cells seem to be relevant. These are NOX1, DUOX1, iNOS or nNOS in tumor cells or neural origin. Gradual inhibition of catalase initially allows NO/PON signaling, as seen by the effects of knockdown of NOX1 and NOS, whereas at higher concentrations of catalase inhibitor, $\mathrm{HOCl}$ signaling prevails, as seen by the knockdown of DUOXI and NOXI. The results of the knockdown experiments are shown to be conclusive, according to the additional control through inhibitor experiments. Furthermore, as supplementation with MPO abrogated the effect of knockdown of DUOX, and supplementation of the NO donor SNP abrogated the effect of knockdown of iNOS, the specificity of the respective siRNA treatment was confirmed. There is no experimental way to control the effect of knockdown of NOX1 by supplementation with a superoxide anion-generating system, as this would require a superoxide anion generating system that acted exclusively in close vicinity of the cell membrane as overall superoxide anion synthesis has an inhibitor effect on intercellular ROS/RNS signaling (30). This negative effect 


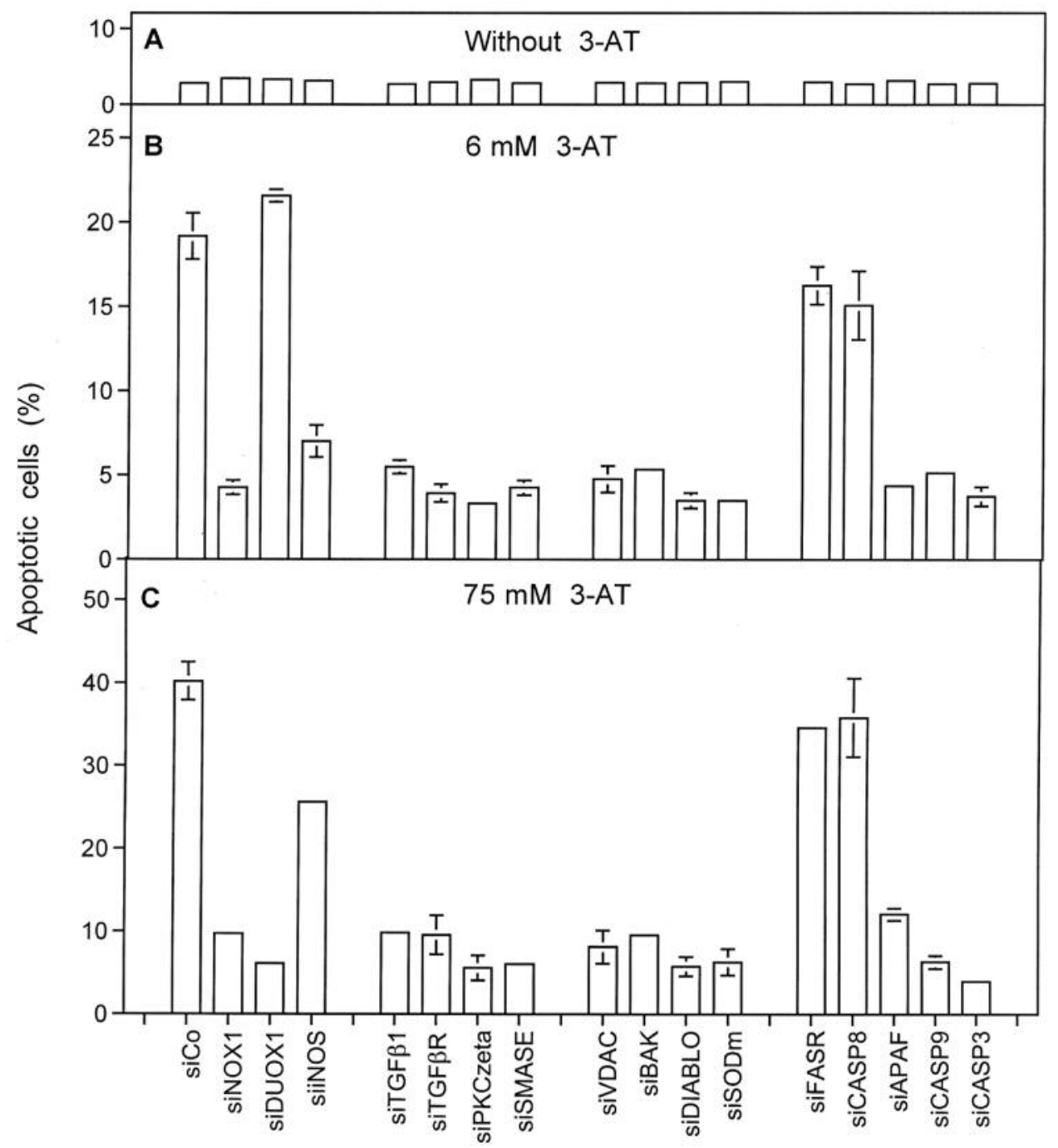

Figure 7. Small interfering ribonucleic acid (siRNA)-based analysis of autocrine apoptosis induction by the nitric oxide/peroxynitrite (NO/PON) and the $\mathrm{HOCl}$ signaling pathway in MKN-45 cells after differential inhibition of catalase by 3-aminotriazole (3-AT). As determined by preceding inhibition studies, $6 \mathrm{mM}$ 3-AT reactivated NO/PON signaling, whereas $75 \mathrm{mM}$ 3-AT caused reactivation of HOCl signaling. The figure shows the effect of knockdown of essential molecular players on these signaling events. Compared to control siRNA (siCo), siRNA directed towards NADPH oxidase-1 (siNOX1), transforming growth factor $\beta 1$ (siTGF $\beta 1)$, TGF $\beta$ receptor (siTGF $\beta R$ ), protein kinase $C$ zeta (siPKC zeta), acidic sphingomyelinase (siSMase), voltage-dependent anion channel (siVDAC), bcl-2 homologous antagonist/killer (siBAK), mitochondria-derived activator of caspases (siDiablo), mitochondrial superoxide dismutase (siSODm), apoptosis protease activating factor (siAPAF), caspase-9 (siCASP9) and caspase-3 (siCASP-3) caused strong inhibition of apoptosis at $6 \mathrm{mM}$ and $75 \mathrm{mM}$ 3-AT, whereas siRNA directed towards the FAS receptor (FASR) and caspase-8 (siCASP8) had no effect at both concentrations of 3-AT. SiRNA directed towards dual oxidase-1 (siDUOX1) had no effect at 6 mM 3-AT, but caused strong inhibition at $75 \mathrm{mM}$ 3-AT. In contrast, siRNA directed towards inducible NO synthase (siiNOS) caused a strong inhibitory effect at $6 \mathrm{mM}$ 3-AT and a marginal inhibitory effect at $75 \mathrm{mM}$ 3-AT.

is due to direction of generation of central elements such as hydroxyl radicals or PON away from the target cell membrane (30). However, control experiments ensured that the effect of knockdown of NOXI resulted in a reduction of extracellular superoxide generation to less than $10 \%$ that of the control. Based on the cell impermeability of SOD used for this determination, the extracellular localization of NOX1- derived superoxide anions was assured. Likewise, the effect of knockdown of DUOXI was also directly determined by a strong decrease in peroxidase release from siRNA-treated cells, following the analysis recently described (28).

Knockdown of $T G F \beta 1$ or the TGF $\beta R$ in tumor cells had a very strong inhibitory effect on intercellular ROS/RNSdependent apoptosis-inducing signaling at all concentrations 


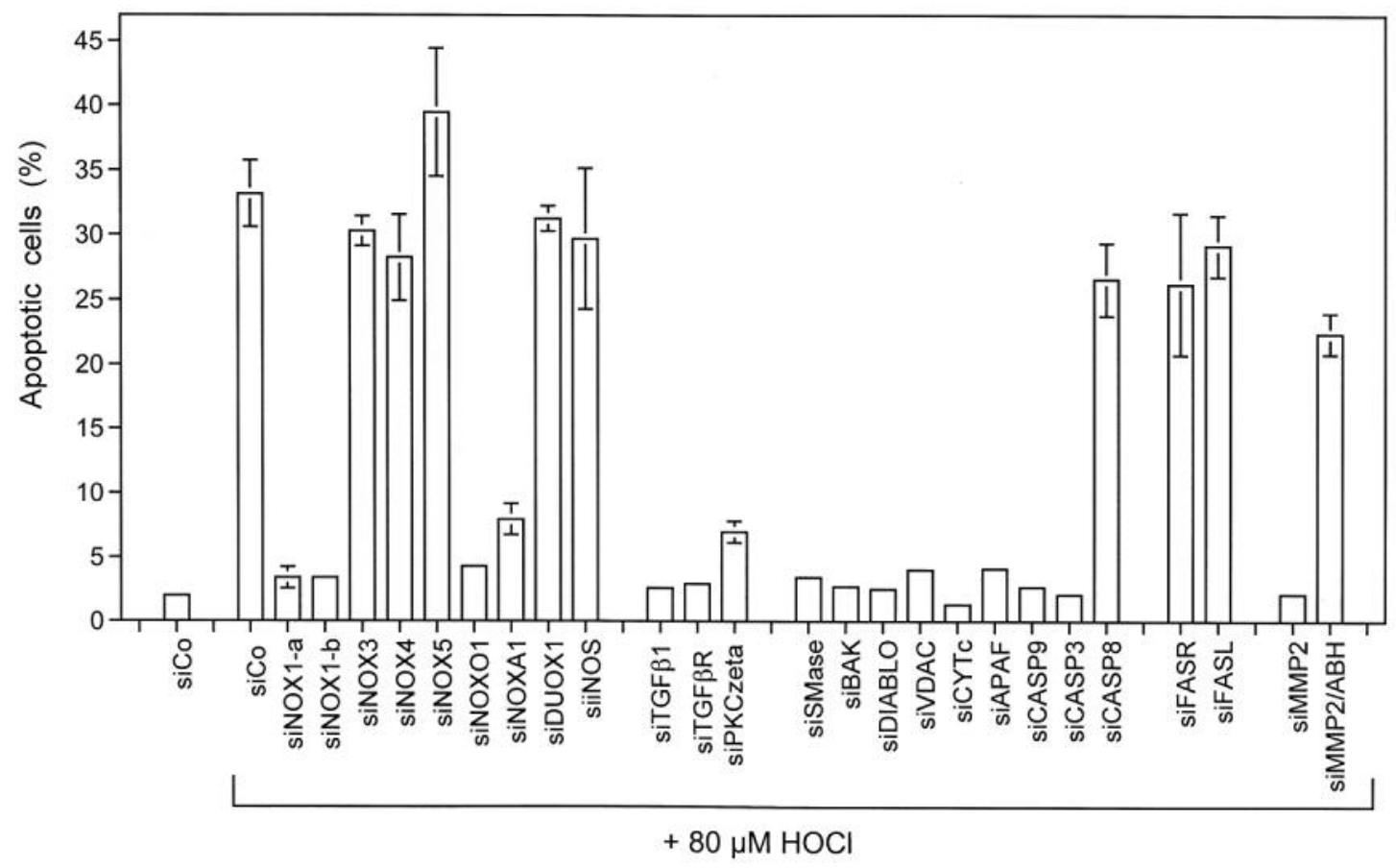

Figure 8. Effect of knockdown of extra- and intracellular signaling molecules on apoptosis induction in MKN-45 cells by exogenous HOCl. Control small interfering ribonucleic acid (siRNA) (siCo), siRNA directed towards NADPH oxidase 1, 3, 4 and 5 (siNOX1, -3, -4, -5), NOX organizer 1 (siNOXO1), NOX1 activator (siNOXA1), dual oxidase-1 (siDUOX1), inducible NO synthase (siiNOS), transforming growth factor $\beta$-1 (siTGF $\beta 1$ ), TGF $\beta$ receptor (siTGF $\beta R$ ), protein kinase C zeta (siPKCzeta), acidic sphingomyelinase (siSMASE), bcl-2 homologous antagonist/killer (siBAK), mitochondria-derived activator of caspases (siDiablo) (siDiablo), voltage-dependent anion chanel (siVDAC), cytochrome c (siCYTc), apoptosis protease activating factor (siAPAF), caspase-9, -3 and -8 (siCASP9, -3, -8), FAS receptor (siFASR), FAS ligand (siFASL), matrix metalloproteinase2 (siMMP2) and siMMP2 plus $150 \mu M$ 4-amino benzoyl hydrazide $(\mathrm{ABH})$.

of the catalase inhibitor. The specificity of this approach was assured as the effect of siTGF $\beta 1$ was compensated for by the addition of exogenous TGF $\beta 1$, whereas the effect of siTGF $\beta R$ was not, as expected. This finding shows that tumor cells seem to produce sufficient concentration of TGF $\beta 1$ required for the control of their intercellular signalling and also have a functional receptor to react to their own TGF $\beta 1$. In contrast, transformed cells such as 208FSrc 3 cells seem to produce less TGF $\beta 1$ and therefore require supplementation with exogenous TGF $\beta 1$ under experimental conditions. Based on our analysis, TGF $\beta 1$ seems to have two central targets in this context: it seems to control the activity of NOX1 (27) and to drive the release of the peroxidase domain of DUOX that is split from DUOX by the action of MMP (28). The strong inhibitory effect of knockdown of PKCzeta is in line with these findings, as PKC zeta is involved in the control of NOX1 (31) and a partial dependence of DUOX-coded POD release on PKC zeta was directly demonstrated here.

The combination of the siRNA-based data obtained here with results obtained in recently published inhibitor and reconstitution experiments now allows a rather complete picture to be drawn of the extracellular ROS/RNS-dependent signaling pathways of tumor cells with inhibited or inactivated catalase: i) TGF $\beta 1$ and its receptor control the activity of NOX1 and the release of the POD domain from DUOX1; ii) NOX1 generates extracellular superoxide anions that either dismutate to $\mathrm{H}_{2} \mathrm{O}_{2}$, or react with $\mathrm{HOCl}$ to generate hydroxyl radicals or react with $\mathrm{NO}$, resulting in the formation of PON; iii) the POD domain of DUOX generates $\mathrm{HOCl}$, utilizing $\mathrm{H}_{2} \mathrm{O}_{2}$ as substrate; iv) the interaction between $\mathrm{HOCl}$ and $\mathrm{NOX} 1$-derived superoxide anions yields hydroxyl radicals in close vicinity to the cell membrane, resulting in lipid peroxidation; v) PON generated through the interaction between NOX1-derived superoxide anions and NOS-derived NO is protonated by proton pumps in the membrane and yields peroxynitrous acid. Peroxynitrous acid then decomposes into $\mathrm{NO}_{2}$ and hydroxyl radicals. PON that diffuses away from the membrane preferentially reacts with $\mathrm{CO}_{2}$ and does not contribute to apoptosis induction (5).

The siRNA-based analysis of tumor cells in which the $\mathrm{NO} / \mathrm{PON}$ or $\mathrm{HOCl}$ signaling pathway are differentially expressed by use of adequate concentrations of the catalase inhibitor 3-AT or in which these two pathways are separately and selectively induced through the addition of $\mathrm{HOCl}$ or $\mathrm{NO}$ 


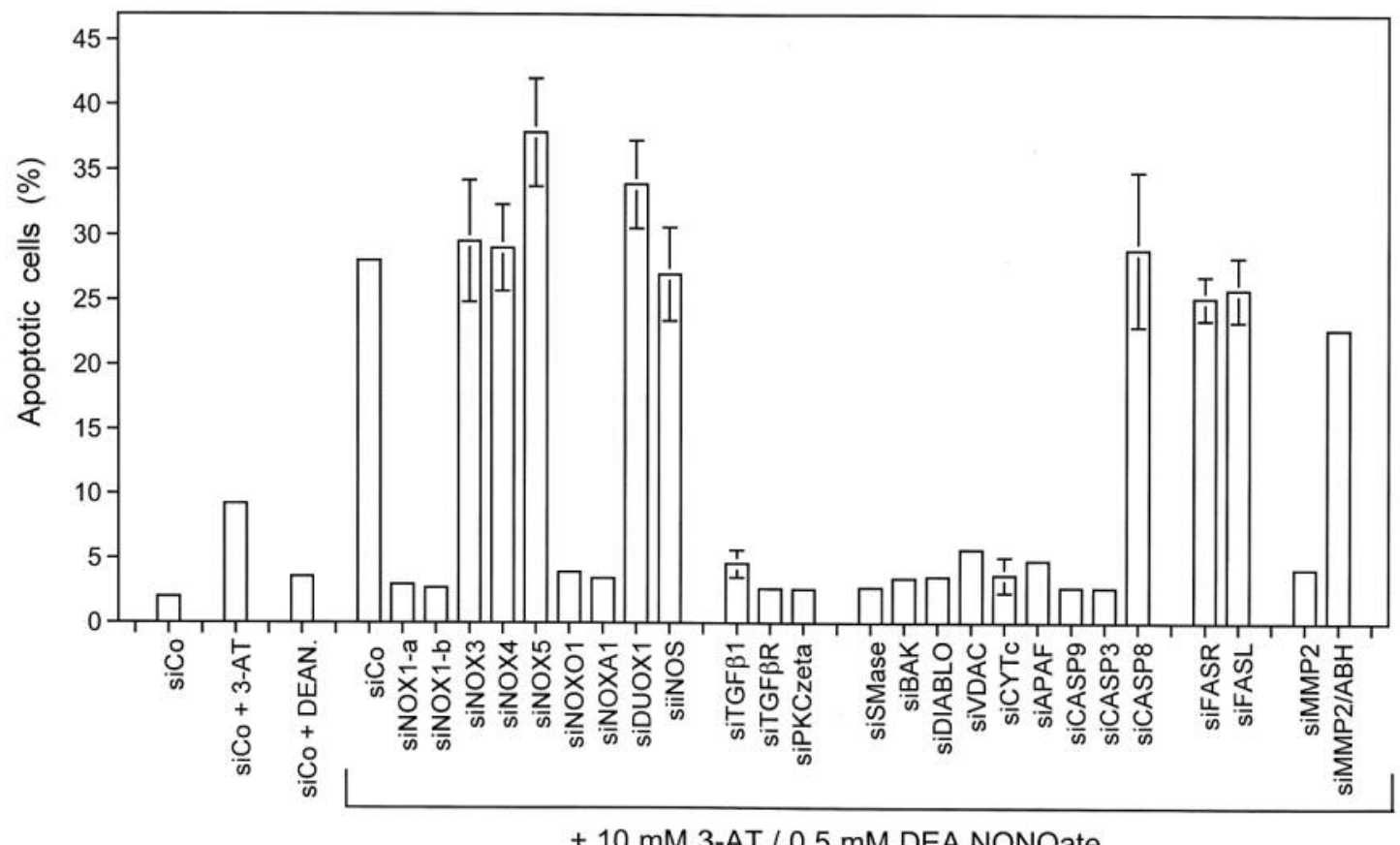

Figure 9. Effect of knockdown of extra- and intracellular signaling molecules on apoptosis induction in MKN-45 cells by the exogenous NO donor diethylamine NONOate (DEA NONOate). MKN-45 tumor cells transfected with control small interfering ribonucleic acid (siRNA) (siCo) did not show substantial apoptosis induction when cultured alone or in the presence of $10 \mathrm{mM}$ 3-aminotriazole (3-AT) or 0.5 mM DEA NONOate (siCo + DEAN). Apoptosis was induced in siCo cells when $10 \mathrm{mM}$ 3-AT and $0.5 \mathrm{mM}$ DEA NONOate were combined. The figure shows the differential effect of knockdown of extra- and intracellular players on apoptosis induction in the presence of $10 \mathrm{mM}$ 3-AT and 0.5 mM DEA NONOate. Control small interfering ribonucleic acid (siRNA) (siCo), siRNA directed towards NADPH oxidase 1, 3, 4 and 5 (siNOX1, -3, -4, -5), NOX organizer 1 (siNOXO1), NOX1 activator (siNOXA1), dual oxidase-1 (siDUOX1), inducible NO synthase (siiNOS), transforming growth factor $\beta$-1 (siTGF 1 ), TGF $\beta$ receptor (siTGFRR), protein kinase C zeta (siPKCzeta), acidic sphingomyelinase (siSMASE), bcl-2 homologous antagonist/killer (siBAK), mitochondriaderived activator of caspases (siDiablo) (siDiablo), voltage-dependent anion chanel (siVDAC), cytochrome c (siCYTc), apoptosis protease activating factor (siAPAF), caspase-9, -3 and -8 (siCASP9, -3, -8), FAS receptor (siFASR), FAS ligand (siFASL), matrix metalloproteinase-2 (siMMP2) and siMMP2 plus $150 \mu M$ 4-amino benzoyl hydrazide $(A B H)$.

(in the presence of $10 \mathrm{mM} 3-\mathrm{AT}$ ) allowed the description of $\mathrm{HOCl} /$ superoxide anion interaction, $\mathrm{NO} /$ superoxide anion interaction and of the intracellular events following lipid peroxidation through hydroxyl radicals derived from $\mathrm{HOCl}$ or NO/PON signaling. Thereby, the role of NOX1 and its associated activities NOX1 organizer and NOX1 activator (32) were confirmed. Most likely, lipid peroxides generated through the action of hydroxyl radicals activate SMAse (33, 34). The strong effect of the knockdown of SMAse indicates that ceramides might indeed play a crucial role in intracellular signalling pathways after ROS/RNS-dependent extracellular effects. Ceramides have been shown to target mitochondria to trigger the mitochondrial pathway of apoptosis (35-37). In line with this assumption, knockdown of central elements of the mitochondrial pathway of apoptosis (38-40), such as BAK, DIABLO, mitochondrial SOD, APAF, and caspase-9 had a strong inhibitory effect on apoptosis induction in 3-AT-treated tumor cells. VDAC seems to play a central role for apoptosis induction as well.
The exact function of VDAC is, however, a matter of scientific dispute (41). The effect of the knockdown of caspase 3 may be taken as an indication that this is the final executing caspase, triggered by caspase- 9 , whereas the death receptor-dependent pathway through FASR, FASL and caspase-8 do not seem to play a role here.

As the release of cytochrome $c$ during the execution of the mitochondrial pathway of apoptosis causes a breakdown of the respiratory chain, free superoxide anions are generated and dismutated to $\mathrm{H}_{2} \mathrm{O}_{2}$ by mitochondrial SOD. This increase in intracellular ROS is a consequence of apoptosis induction and has to be clearly differentiated from the initial extracellular ROS/RNS effects that trigger the onset of apoptosis induction.

The literature on apoptosis usually differentiates between an extrinsic pathway, mediated by death receptors, and the intrinsic mitochondrial pathway. However, the findings here show that the mitochondrial pathway can also be triggered by extrinsic ROS/RNS signaling that targets the membrane without affecting death receptors. Therefore, this suggests the 
need to differentiate between extrinsic death receptordependent and extrinsic death receptor-independent pathways mediated by the intracellular mitochondrial pathway. It also suggests the term "intrinsic apoptosis induction" should be used only when the initial signal is truly acting inside the cells.

Interestingly, the siRNA-based analysis given in Figures 8 and 9 also shows that knockdown of $M M P 2$ caused inhibition of apoptosis induction by exogenous $\mathrm{HOCl}$ or $\mathrm{NO}$. As its inhibition was abrogated by the peroxidase inhibitor $\mathrm{ABH}$, it seemed to depend on an enzymatic reaction of peroxidase. This finding is explained by the destruction of $\mathrm{HOCl}$ and oxidation of $\mathrm{NO} /$ decomposition of PON by membrane-associated peroxidase domain of DUOX1 (30). This finding, therefore, explains the need for the release of the POD for functioning signalling pathways and also points out the dependency of intercellular ROS/RNS signalling on specific steric constellations.

\section{Acknowledgements}

The Author thanks J. Brandel (Freiburg) for technical support and acknowledges support from RiscRad, EuroTransBio (ETB1 0315012B), Hans-Sauer-Stiftung and COST Action CM0603.

\section{References}

1 Jürgensmeier J, Schmitt CP, Viesel E, Höfler P and Bauer G: TGF$\beta$-treated normal fibroblasts eliminate transformed fibroblasts by induction of apoptosis. Cancer Res 54: 393-398, 1994.

2 Herdener M, Heigold S, Saran M and Bauer G: Target cellderived superoxide anions cause efficiency and selectivity of intercellular induction of apoptosis. Free Radical Biol Med 29: 1260-1271, 2000.

3 Pottgiesser S, Heinzelmann S and Bauer G: Intercellular HOClmediated apoptosis induction in malignant cells: interplay between NOX1-dependent superoxide anion generation and DUOX-related HOCl-generating peroxidase activity. Anticancer Res 35: 5927-5943, 2015.

4 Bauer G: Tumor cell protective catalase as a novel target for rational therapeutic approaches based on specific intercellular ROS signaling. Anticancer Res 32: 2599-2624, 2012.

5 Bauer G: Increasing the endogenous NO level causes catalase inactivation and reactivation of intercellular apoptosis signaling specifically in tumor cells. Redox Biol 6: 353-371, 2015.

6 Heigold S, Sers C, Bechtel W, Ivanovas B, Schäfer R and Bauer G: Nitric oxide mediates apoptosis induction selectively in transformed fibroblasts compared to nontransformed fibroblasts. Carcinogenesis 23: 929-941, 2002.

7 Irani K, Xia Y, Zweier JL, Sollott SJ, Der CJ, Fearon ER, Sundaresan M, Finkel $\mathrm{T}$ and Goldschmidt-Clermont PJ: Mitogenic signalling by oxidants in Ras-transformed fibroblasts. Science 275: 1649-1652, 1997.

8 Heinzelmann S and Bauer G: Multiple protective functions of catalase against intercellular apoptosis-inducing ROS signaling of human tumor cells. Biol Chem 391: 675-693, 2010.

9 Bauer G: Targeting extracellular ROS signaling of tumor cells. Anticancer Res 34: 1467-1482, 2014.
10 Bauer G: Elimination of transformed cells by normal cells: a novel concept for the control of carcinogenesis. Histol Histopathol 11: 237-255, 1996.

11 Kundrát P, Bauer G, Jacob P and Friedland W: Mechanistic modelling suggests that the size of pre-neoplastic lesions is limited by intercellular induction of apoptosis in oncogenically transformed cells. Carcinogenesis 33: 253-259, 2012.

12 Deichman G: Natural selection and early changes of phenotype of tumor cells in vivo: Acquisition of new defense mechanisms. Biochem 65: 78-94, 2000.

13 Deichman G: Early phenotypic changes of in vitro transformed cells during in vivo progression: possible role of the host innate immunity. Sem Cancer Biol 12: 317-326, 2002.

14 Bechtel W and Bauer G: Catalase protects tumor cells against apoptosis induction by intercellular ROS signaling. Anticancer Res 29: 4541-4557, 2009.

15 Böhm B, Heinzelmann S, Motz M and Bauer G: Extracellular localization of catalase is associated with the transformed state of malignant cells. Biol Chem 396: 1339-1356, 2015.

16 Brown GC: Reversible binding and inhibition of catalase by nitric oxide. Eur J Biochem 232: 188-191, 1995.

17 Brunelli L, Yermilov V and Beckman JS: Modulation of catalase peroxidatic and catalatic activity by nitric oxide. Free Rad Biol Med 30: 709-714, 2001

18 Bauer G and Motz M: The antitumor effect of single-domain antibodies directed towards membrane-associated catalase and superoxide dismutase. Anticancer Res 36: 5945-5956, 2016.

19 Bauer G: The antitumor effect of singlet oxygen. Anticancer Res 36: 5649-5664, 2016.

20 Bauer G and Graves DB: Mechanisms of selective antitumor action of cold atmospheric plasma-derived reactive oxygen and nitrogen species. Plasma Process Polymers 13: 1157-1178, 2016.

21 Bauer G, Höfler P and Simon M: Epstein-Barr virus induction by a serum factor II. Purification of a high molecular weight protein that is responsible for induction. J Biol Chem 257: 11405-11410, 1982

22 Wyllie AH, Kerr JF and Currie AR: Cell death: the significance of apoptosis. Int Rev Cytol 68: 251-274,1980.

23 Elmore S: Apoptosis: a review of programmed cell death. Toxicol Pathol 35: 495-516, 2007.

24 Bauer G, Bereswill S, Aichele P and Glocker E: Helicobacter pylori protects oncogenically transformed cells from reactive oxygen species-mediated intercellular induction of apoptosis. Carcinogenesis 35: 1582-1591, 2014.

25 Scheit K and Bauer G: Direct and indirect inactivation of tumor cell protective catalase by salicylic acid and anthocyanidins reactivates intercellular ROS signaling and allows for synergistic effects. Carcinogenesis 36: 400-411, 2015.

26 Bauer G: Low-dose irradiation enhances specific signaling components of intercellular reactive oxygen-mediated apoptosis induction. J Phys Conf Ser 261: 012001, 2011.

27 Temme J and Bauer G: Low-dose gamma irradiation enhances superoxide anion production by nonirradiated cells through TGF- $\beta 1$-dependent bystander signaling. Rad Res 179: 422-432, 2013.

28 Abdelrazzak AB, Pottgießer SJ, Hill MA, O'Neill P and Bauer $\mathrm{G}$ : Enhancement of peroxidase release from non-malignant and malignant cells through low-dose irradiation with different radiation quality. Radiation Res 185: 199-213, 2016. 
29 Schwieger A, Bauer L, Hanusch J, Sers C, Schäfer R and Bauer G: Ras oncogene expression determines sensitivity for intercellular induction of apoptosis. Carcinogenesis 22: 13851392,2001

30 Heinzelmann S and Bauer G: Site-specific effects of DUOX1related peroxidase on intercellular apoptosis signaling. Anticancer Res 35: 5955-5971, 2015.

31 Fontaye A, Dang P M-C, Gougerot-Pocidalo M-A and Benna JE: Phosphorylation of 447 phox sites by PKC $\alpha, \beta I I, \delta$ and $\xi$ : Effect on binding to p22phox and on NADPH oxidase activation. Biochemistry 41: 7743-7750, 2002.

32 Brandes RP, Weissmann $\mathrm{N}$ and Schröder K: NOX family NADPH oxidases: molecular mechanisms of activation. Free Radic Biol Med 76: 208-226, 2014.

33 Loidl A, Claus R, Ingolic E, Deigner H-P and Hermetter A: Role of ceramide in activation of stress-associated MAP kinases by minimally modified LDL in vascular smooth muscle cells. Biochem Biophys Acta 1690: 150-158, 2004.

34 Loidl A, Sevcsik E, Riesenhuber G, Deigner H-P and Hermetter A: Oxidized phospholipids in minimally modified low density lipoprotein induce apoptotic signaling via activation of acid sphingomyelinase in arterial smooth muscle cells. J Biol Chem 278: 32921-32928, 2003.
35 Kolesnik RN and Krönke M: Regulation of ceramide production and apoptosis. Ann Rev Physiol 60: 643-665, 1998.

36 Pettus BJ, Chalfant CE and Hannun YA: Ceramide in apoptosis: an overview and current perspectives. Biochem Biophys Acta 1585: 114-125, 2002.

37 Hannun YA and Obeid LM: Ceramide: an intracellular signal for apoptosis. Trends Biol Sci 20: 73-77, 1995.

38 Zamzami N and Kroemer G: The mitochondrion in apoptosis: how Pandora's box opens. Nat Rev Mol Cell Biol 2: 67-71, 2001.

39 Fulda S, Galluzzi L and Kroemer G: Targeting mitochondria for cancer therapy. Nat Rev Drug Discov 9: 447-464, 2010.

40 Oberst A, Bender C and Green DR: Living with death: the evolution of the mitochondrial pathway of apoptosis in animals. Cell Death Differentiation 15: 1139-1146, 2008.

41 Rostovtseva TK, Tan W and Colombini M: On the role of VDAC in apoptosis: fact and fiction. J Bioenergetics Biomemb 37: 129-142, 2005.

Received November 19, 2016

Revised January 9, 2017

Accepted January 17, 2017 